\title{
MODELAGEM DO VESTUÁRIO A PARTIR DAS PERCEPÇÕES DOS PROFESSORES EM SANTA CATARINA
}

\section{GARMENT MODELING FROM THE PERCEPTIONS OF PROFESSORS IN SANTA CATARINA}

Maicon Douglas Livramento Nishimura ${ }^{1}$ Lizandra Garcia Lupi Vergara² Leila Amaral Gontijo ${ }^{3}$ 


\section{Resumo}

A modelagem é um processo fundamental para o desenvolvimento do produto de moda, afinal, é por meio dele que se concebe fisicamente a roupa. Entretanto, muitos defeitos que se apresentam no mercado poderiam ser evitados nessa etapa, a partir da adequação da peça às questões de usabilidade e o uso de medidas compatíveis com o público que se almeja atingir. Ao partir da premissa que $o$ mercado tem buscado profissionais qualificados, com formações na área de moda, para ocupar o cargo de estilista, buscou-se conhecer sobre as percepções de professores sobre a etapa de modelagem no processo de desenvolvimento do produto de moda. Utilizou-se de entrevista semiestruturada para o levantamento dos dados e da análise de conteúdo para o tratamento dos mesmos. Participaram da pesquisa 15 professores de modelagem da Grande Florianópolis e do Vale do Itajaí e foi possível perceber que eles consideram a disciplina de grande importância para o desenvolvimento do produto de moda, porque é nessa etapa que o produto se materializa e a roupa é pensada ergonomicamente.

Palavras-Chave: Modelagem do vestuário; Professores; Ergonomia.
Garment modeling is a fundamental process for the development of the fashion product, after all, it is through it that the clothing is physically conceived. However, many defects in the market could be avoided at this stage, from the suitability of the clothes to usability issues and the use of measures compatible with the public that aims to achieve. Based on the premise that the market has sought qualified professionals with training in fashion to occupy the position of stylist, we sought to know about the perceptions of Professors about the modeling stage in the process of development of the fashion product. A semi-structured interview was used to collect the data and analyze the content for the treatment of the data. 15 modeling professors from Grande Florianópolis and Vale do Itajaí participated in the survey and it was possible to perceive that they consider the discipline of great importance for the development of the fashion product, because it is at this stage that the product materializes and the clothing is ergonomically designed.

Keywords: Garment modeling; Professors; Ergonomics.

ISSN: 1808.3129

\footnotetext{
1 maiconnishimura@yahoo.com.br

2 l.vergara@ufsc.br

3 leila.gontijo@ufsc.br
} 


\section{INTRODUÇÃO}

A profissão de modelista possui uma das melhores remunerações na cadeia produtiva de moda. Isso ocorre porque não há uma grande de quantidade de profissionais qualificados para exercer o cargo e a etapa da modelagem é fator determinante para a materialização do croqui de moda e para a conformidade do produto às questões de usabilidade.

Com isso, cabe então ao modelista realizar a interpretação do desenho técnico com precisão, sempre atento ao melhor aproveitamento dos materiais disponíveis, a adequação da criação do estilista ao usuário final, seja em relação às medidas antropométricas compatíveis, assim como em acabamentos que proporcionem maior conforto na hora de utilizar a peça.

Pode-se desenvolver a modelagem de forma bidimensional, diretamente no papel, ou por meio da moulage, que consiste em manipular o tecido no manequim ou no corpo. Esta segunda técnica é mais utilizada no vestuário sob medida, devido a sua personalização, e a técnica da modelagem bidimensional ou plana é mais difundida na indústria.

Contudo, a falta de experiência, formação e informação pode colocar em risco a qualidade da roupa. É bastante comum se ouvir queixas a respeito de medidas, caimento, desconforto causado por algum tipo de material ou acabamento. Esses problemas podem ser evitados caso a etapa de modelagem seja executada com acuidade pela empresa.

Baseado nessa realidade, expandiu-se a oferta de cursos de modelagem, seja no programa dos cursos de graduação ou em cursos avulsos oferecidos por instituições públicas ou privadas. No mesmo sentido, a demanda também aumentou e o mercado tem buscado incentivar a capacitação dos seus funcionários e a contratação de pessoas com formação e experiência na área.

Logo, percebe-se a importância de uma disciplina como a modelagem e a sua relevância para a formação profissional na área de moda. $E$, para que esses cursos funcionem, são necessários agentes nesse processo de conhecimento. Pessoas com alta capacitação e experiência para ensinar a outras a técnica de modelar.

Mas, ao refletir sobre a recente criação de cursos de moda, pode-se chegar a um universo de professores que possuem seu conhecimento proveniente da experiência do fazer para o mercado, sem uma formação prévia especializada ou de professores jovens com formação técnica ou acadêmica sem muita experiência profissional.

Com o intuito de conhecer a opinião desses profissionais sobre a modelagem, essa pesquisa se constrói. Tem como objetivo principal conhecer sobre as percepções de professores universitários e de cursos técnicos sobre a etapa de modelagem no processo de desenvolvimento do produto de moda. A pesquisa possui caráter exploratório dentro de uma abordagem quantitativa, afinal, seu objetivo foi o levantamento de dados com uma amostra definida pela técnica de análise de conteúdo (BARDIN, 2009).

\section{MODELAGEM PLANA}

A modelagem plana tem início na interpretação do desenho de moda, passa pelo traçado da modelagem em tamanho real e finaliza o processo com a elaboração dos moldes por meio do uso de bases de qualidade aferida, com atenção para conhecimentos em geometria plana e espacial, assim como em antropometria, de 
acordo com Santos (2015). Em encontro a isso, Silveira (2008) também defende que se a roupa for desenvolvida com um apurado cálculo matemático durante o processo de traçado das bases e as proporções corporais forem respeitadas, o caimento obtido será de alta qualidade e se apropriará de aspectos ergonômicos.

Para que a roupa atenda aos requisitos de conforto, seja em relação a uma folga de movimento adequada a fim de não interferir negativamente no funcionamento do corpo ou com a finalidade de adaptar a peça à atividade executada pelo indivíduo, é fundamental que o designer de moda tenha conhecimento em ergonomia e o aplique naquilo que projeta (BEZERRA E MARTINS, 2013).

Beduschi e Italiano (2013) corroboram com a necessidade de o profissional de modelagem dominar a ergonomia e seus conceitos, como a antropometria, por exemplo. Mas, as autoras ressaltam a necessidade de adaptação da modelagem para outros setores do processo produtivo de moda, como o setor de criação e produção. Nesse contexto, sugerem a ampliação da abrangência do domínio de conhecimentos ergonômicos para toda a cadeia.

Por parte do designer, o domínio de conceitos ergonômicos de usabilidade e antropometria possibilitam o desenvolvimento da coleção de moda com foco, desde o início, naquilo que o público-alvo determina como conforto e com base em medidas que correspondem à realidade do consumidor final (MENEZES E SPAINE, 2010). Características essas que são atribuídas ao produto de vestuário de moda no processo de modelagem.

Do ponto de vista organizacional, problemas de comunicação e integração sempre estão presentes e a busca por soluções é constante para alcançar uma maior produtividade. Na área de moda, contudo, o bom funcionamento desses dois fatores na cadeia produtiva é crucial para o efetivo desenvolvimento do produto. Souza (2006) aborda que as etapas de criação e modelagem compõe o mesmo processo, de desenvolver o produto, apesar de que muitas vezes são alocadas em etapas diferentes. A autora coloca que o raciocínio desses dois profissionais opera de modo disjunto, porém, deveria ser adotado um método para que essas duas áreas pudessem interagir com o intuito de melhorar a qualidade e o desempenho.

Da mesma forma que outros segmentos de mercado, a moda se apoia no conceito de atender, suprir e incitar desejo ao consumidor (BEDUSCHI, 2013). Nesse sentido, cabe ao estilista corresponder aos anseios do consumidor com criatividade e desenvolver o croqui de moda com base na modelagem e conhecimentos ergonômicos (MENEZES E SPAINE, 2010).

Deste modo, com a finalidade de agregar valor ao produto de vestuário, profissionais que atuam na área de modelagem qualificam a etapa como de grande importância. Souza (2006), Menezes e Spaine (2010), Bezerra e Martins (2013), Beduschi e Italiano (2013) e Santos (2015) apresentam a modelagem como um processo de grande responsabilidade que materializa o produto por meio da planificação da roupa e transformação do tecido de artefato bidimensional para tridimensional, conferindo alma para a peça que se produz.

Em relação ao ensino, a modelagem plana recebe atenção como método devido ao fato de ser a técnica mais difundida na indústria, seja no Brasil ou no exterior, de acordo com Beduschi e Italiano (2013). As autoras apontam ainda que a discipli- 
na de modelagem, tanto em importância como em aperfeiçoamento de conteúdo, avançou no Brasil a partir da década de 1960 juntamente com a industrialização do país.

Contudo, mesmo o avanço em metodologias de ensino de modelagem, ainda é recorrente dificuldades na prática. Santos (2015) traz a ideia de que ao se concordar que a modelagem é a alma da roupa, cursos que formam designers de moda devem preparar os futuros profissionais para que tenham domínio dos conhecimentos que envolvem a tarefa de modelar. Como consequência, a demanda do mercado por inovação e novidade será atendida por meio de novas soluções em modelagem.

Menezes e Spaine (2010) ressaltam a importância da etapa de modelagem ao possibilitar a materialização da ideia de um produto e aponta para a necessidade de planejar as etapas seguintes à modelagem com o objetivo de realizar um trabalho interdisciplinar com os setores de produção, comercial e a própria modelagem. Com base nessa percepção de mercado, as autoras levantam o fato de haver pouca integração em grades curriculares de cursos de moda como, por exemplo, o ensino da modelagem sem o conhecimento prévio de ergonomia que é classificado como significativo para o processo de desenvolvimento do produto de moda.

A integração das áreas no processo de desenvolvimento de vestuário é fundamental, assim como a visão do designer de moda. Fletcher e Grose (2011) enfatizam o poder que o designer possui para decidir os elementos que irão compor os processos produtivos, além da coleção, e apontam para a necessidade de uma formação com visão sistêmica para garantir a efetividade do negócio.

\section{METODOLOGIA}

Os dados foram obtidos por meio de entrevista semiestruturada a 15 professores da disciplina de modelagem da região da Grande Florianópolis ou do Vale do Itajaí. Foram escolhidas essas duas regiões porque apresentam uma quantidade representativa de profissionais com o perfil pesquisado devido ao fato de haver importantes instituições que ministram a disciplina de interesse.

Para a realização das entrevistas, inicialmente, foi realizado o contato via e-mail para explicar o objetivo da pesquisa e verificar a disponibilidade dos entrevistados. Em seguida, foram marcados os horários e realizadas as entrevistas na modalidade presencial. Todas as conversas foram gravadas por meio de um aparelho celular e, posteriormente, transcritas. A análise de conteúdo foi realizada com base no material gerado e de acordo com a metodologia de Bardin (2009).

Para a entrevista semiestruturada, desenvolveu-se um questionário que serviu de apoio. Constavam duas categorias de perguntas. A primeira era referente ao perfil da amostra, como sexo, idade, área de atuação, tempo de experiência e cidades que atuava. A outra categoria estava relacionada à importância da modelagem, em que questionava qual era a percepção do entrevistado sobre a etapa de modelagem no desenvolvimento do produto de moda.

A partir das respostas referente à pergunta em relação ao processo de modelagem foram extraídas tipologias para compor a categorização do método de análise 
de conteúdo. Assim, observou-se que as respostas dos professores se enquadravam em três grupos: "etapa mais importante", "materializar o produto" e "analisar o produto ergonomicamente".

\section{RESULTADOS}

As perguntas feitas aos entrevistados se dividiram em duas partes: perfil da amostra e a importância da modelagem. Em perfil da amostra foi possível coletar dados sobre o perfil dos profissionais e, na segunda parte, obteve-se o depoimento sobre a percepção da etapa da modelagem no processo de desenvolvimento do produto de moda.

As entrevistas foram realizadas em três cidades. $47 \%$ dos entrevistados lecionam em Gaspar, 46\% lecionam em Florianópolis e 7\% em Blumenau. Alguns dos entrevistados já deram aulas em outros municípios do estado e até em outros estados do país, mas atualmente estão todos fixos nos municípios apontados.

Dos 15 entrevistados, 12 (80\%) eram do sexo feminino e, apenas três (20\%), do sexo masculino. Além disso, $73 \%$ do total dos entrevistados tinham idade entre 25 e40 anos. Percebeu-se um perfil jovem e predominantemente feminino entre os professores de modelagem de cursos superiores e técnicos da região da Grande Florianópolis e Vale do Itajaí.

Em relação à formação, três dos entrevistados, todos com idade acima de 40 anos, não possuem graduação em moda, mas em outras áreas (economia, geografia, pedagogia). Isso se deve ao fato que na época em que esses profissionais ingressaram na faculdade não havia um curso de graduação em moda. Entretanto, fizeram cursos de pós-graduação na área de moda e dois deles tinham familiaridade com o setor por causa de empresa de confecção das famílias. O outro entrevistado sem graduação em moda havia feito um curso técnico na área têxtil e, por esse meio, conheceu a modelagem.

Do universo da pesquisa, $80 \%$ possuem graduação em moda, $87 \%$ do total deles possuem também pós-graduação em moda. $53 \%$ possui titulação de mestrado e, apenas, $13 \%$ possui doutorado. As pesquisas de mestrado e doutorado dos entrevistados que possuem os títulos foram na área de moda, todavia, os entrevistados cursaram em áreas diversas: engenharia, design, pedagogia. Vale ressaltar que o primeiro curso de mestrado em moda será inaugurado apenas no ano de 2017 na Universidade do Estado de Santa Catarina.

Os entrevistados comentaram que a experiência profissional em confecções foi bastante importante para o aprimoramento na área de modelagem. Alguns deles tinham mais de 10 anos de experiência de mercado, mas, apresenta-se aqui o tempo de experiência como ministrante da disciplina de modelagem. 13\% responderam que tinha experiência de até 2 anos. De 3 a 5 anos e de 6 a 10 anos reuniu 27\% dos entrevistados, cada. 13\% dos professores tinham de 11 a 15 anos. E 20\% responderam estar há mais de 21 anos na área de ensino de modelagem.

Com base na metodologia de análise de conteúdo, levantou-se algumas falas frequentes da segunda parte da entrevista e se verificou a frequência delas entre os 
Modelagem do vestuário a partir das percepções dos professores em santa catarina

professores. Todos apontaram a modelagem como uma das etapas mais importante do processo de desenvolvimento do produto de moda, 46,67\% disseram que a etapa de modelagem é a que materializa o produto e, também, 46,67\% falaram que é nessa etapa que se analisa o produto ergonomicamente. No quadro 1 podem ser observadas algumas verbalizações que reforçam os percentuais apresentados.

\title{
Quadro 1. Verbalizações sobre a importância da modelagem no desenvolvi- mento do produto de moda
}

\begin{abstract}
R01: [...] Então a modelagem que dá vida ao produto. Então aonde tem que ter toda a qualidade, porque é onde começa tudo. No setor de modelagem. Então, se a modelagem não for bem feita coloca em risco todo o desenvolvimento da coleção.

R02: [...] Ela bem... bem importante e se você tem noção, né, de modelagem, de, ãhn... ergonomia, de anatomia... A possibilidade de você acertar já, inicialmente, ela é bem alta assim.

R04: [...] Então, acho que é muito difícil ter a concepção de um produto novo sem conhecer a modelagem pra saber o que é possível fazer e o que também é necessário fazer pra que o corpo tenha conforto ao usar a peça.

R05: [...] Mas que é fundamental, claro, a gente conhecer as... as medidas do corpo humano pra desenvolver o produto, mas, além disso, a gente também tem que entender de que forma os movimentos do corpo humano, né... vão interagir com... com o produto, né? Então, o corpo humano como objeto pra se interagir com essa roupa. [...].

R06: [...] E eu entendo a modelagem como ainda integrante da parte bem de concepção ainda assim, até... até como uma possibilidade de criação eu acho. Porque eu acho que quando a criação, ela se desvincula muito modelagem, o produto final acaba, eh... a chance de ter problemas é muito maior, né? [...].
\end{abstract}

R08: [...] A importância que se deve dar a essa etapa do processo acho que... acho que assim, a qualidade, a qualidade da peça vai depender, eh... da modelagem. Então, a questão de caimento, a questão de a roupa servir ou não, até parte de... do diferencial da peça assim que eu acho que muita gente presta atenção nisso na hora de comprar uma roupa. [...].

R09: Bem, a importância é tu conhecer tanto a parte antropométrica, que seria o estudo do corpo... da proporção do corpo e como isso leva pra construir as bases. Porque tu precisa ter esse conhecimento pra saber direcionar qual base que tu vai trabalhar e qual a interpretação. Claro que o corpo somente, ele não é ainda, ãhn... conhecimento suficiente, tu também tem que tá bem informado sobre os tecidos que tu vai usar... E a forma que tu querer dar praquilo, né? [...].

R10: [...] É um dos determinantes de... mas em relação à vestibilidade, não em relação à beleza, né? A beleza daí vai ter outros fatores que vão influenciar, né? Mas em termos de vestibilidade é a modelagem que vai determinar também, né? [...].

R15: [...] Então acho a área de modelagem um dos fatores que mais seria o fator, no meu ver, um dos fatores primordial assim... Do processo. Porque sem uma boa modelagem ou o modelista entender que tecido que ele tá trabalhando, que tem caimento ou não tem caimento. [...]. 
Um dos aspectos apontados pelos respondentes e que pode ser conferida na fala do respondente 01 (R01), presente no quadro 1, é que a modelagem determina o ponto de partida para a materialização do produto final, a roupa, e esse processo é decisório para fornecer qualidade para aquilo que se desenvolve com o intuito de gerar diferenciação no mercado em que se almeja comercializar.

Assim como R01 comenta sobre a qualidade, R02, R04, R05, R08, R9, R10 e R15 trazem a noção de antropometria e/ou ergonomia para o seu discurso. Eles apontam a necessidade de alinhar a proposta de produto em termos que visem quesitos de usabilidade e estejam atentos às medidas antropométricas, porque é nessa fase de desenvolvimento em que é possível realizar as adequações.

A respondente 06 compartilha da visão dos demais, entretanto, traz uma proposta diferente, de utilizar a modelagem como técnica de criação. Justifica que a criação e a modelagem necessitam caminhar acompanhadas a fim de não tornar o produto em algo desconexo ou inviabilizado. Dessa maneira, mostra que a modelagem pode ser o início para a criação, ao invés do tradicional croqui de moda.

No quadro 2 é possível visualizar algumas falas que não estão diretamente ligadas à pergunta feita aos respondentes, porém, seu conteúdo é de interesse pois reforça algumas ideias trazidas por todos como questões relacionadas ao mercado. $O$ peso da experiência em confecções, a realidade das empresas e a modelagem como fator de diferenciação de mercado.

\section{Quadro 2. Verbalizações complementares}

R09: [...] Então, às vezes eu acho engraçado quando alguém não tem essa formação, não tem esse
conhecimento dentro de uma universidade, ou seja, mesmo empírico, porque eu aprendi fazendo,
né? Aprendi errado. Né? E a gente não tinha mesmo livro, não tinha nada, era fazer mesmo, sou
filha de costureira então... fazer. É. Tentativa e erro até acertar. Depois tu descobre que existe um
método pra fazer aquilo. Ou até mesmo tu cria o teu próprio método, né? [...].
R11: [...] Então assim... e eu sempre preguei pros alunos, - e prego -, às vezes eu até digo pra eles
assim, principalmente quando é graduação, né? Que eles acham, "ah, eu vou ser estilista", aí eles
acham que modelagem na... no conteúdo programático é só algo pra encher linguiça. Um enfeite.
Depois, eles voltam, né? “Ai professor, eu preciso de explicação sobre tal coisa que no dia lá da
aula eu não prestei atenção". Porque se tu não tiver uma boa modelagem, tu não tem nada, né? [...].
R14: [...] Todo estilista deveria saber um tiquinho... Um tiquinho, bastante de modelagem, essa é
a minha visão, porque... mas eu mudei essa opinião com... com a experiência profissional assim.
Porque eu... eu não tinha essa visão não. Pra tu... e quando tu vai trabalhar em empresa, né? Aí tu
vai... como estilista e tu vai repassar pro modelista o quê que tu quer fazer e não sabe explicar como
é que a modelista vai fazer aquilo... daí não tem muita conversa assim, então, tem que saber um
pouquinho.


A respondente 09 relata que iniciou no setor de confecção antes mesmo de possuir uma formação na área. Sua mãe era costureira e foi por aí que surgiu o primeiro contato com a moda. Apesar de hoje ser professora universitária com título de mestre em educação, analisa seu aprendizado na metodologia da experimentação. Quando começou não tinha o conhecimento presente nos livros, mas uma bagagem trazida do método de tentativa e erro.

Dois dos respondentes, R11 e R14, comentam da importância do profissional que atua como estilista ter conhecimento de modelagem. R11 fala que seus alunos não dão a devida importância para a disciplina, no entanto, quando entram no mercado de trabalho sentem a necessidade desse conhecimento técnico. R14 reforça o exposto de R11 ao trazer a mesma situação, porém no papel de aluna que precisou retomar seus estudos de modelagem.

Ainda no sentido de posicionar a importância da modelagem no mercado, R15 traz a modelagem como fator de diferenciação para o produto e ressalta, assim, a necessidade dessa etapa. Seu discurso se aproxima de R06, que traz a possibilidade de incluir a modelagem na etapa de concepção do produto, a criação.

\section{CONCLUSÃO}

A partir do perfil profissional resultante da pesquisa foi possível identificar uma predominância de pessoas do sexo feminino, com mais de 6 anos de experiência como professor da disciplina de modelagem e, exceto por um respondente, todos possuem pós-graduação em moda, seja lato sensu ou stricto sensu. Portanto, verifica-se que os indivíduos que participam na formação de novos profissionais possuem formação considerável para uma área acadêmica recente.

Como atuante de qualquer área, é comum que as pessoas defendam aquilo que fazem como prioridade em uma instituição. Pode-se observar, entre os modelistas, que eles elegem a etapa de modelagem do vestuário como prioridade na cadeia produtiva de moda. Igualmente, a revisão bibliográfica reforça a opinião dos entrevistados. A modelagem é de fato, se não a mais importante, uma etapa definitiva para o desenvolvimento de uma peça de roupa.

Contudo, Souza (2006) e Beduschi e Italiano (2013) trazem o questionamento da integração dos setores de uma empresa. Em uma realidade competitiva e veloz, o bom relacionamento de uma equipe de desenvolvimento de produto é determinante para o melhor desempenho em relação à produtividade. Assim, a interação entre a criação e a modelagem pode possibilitar a economia de tempo para ambos os setores e garantir uma melhor qualidade à peça por ter sido planejado em conjunto e respeitar aspectos de conforto e estética.

Além disso, o papel da modelagem é categórico no desenvolvimento do produto de moda porque possibilita desde a idealização do produto final, como abordou - R06, materialização do croqui de moda por dimensionar em forma e tamanho a concepção do setor de criação e agregação, sobretudo, de aspetos ergonômicos se devidamente projetado. 
Ainda, a modelagem possui grande importância para todo o processo por possibilitar diferenciais ao produto. A empresa que possui uma base de modelagem com apoio em medidas antropométricas adequadas ao usuário, um tracejado anatômico, equilíbrio entre as formas poderá obter um produto com um caimento singular e se destacar no mercado em que estiver inserido, conforme também abordado por Silveira (2008), Santos (2015) e o R15.

Os autores consultados na revisão bibliográfica apresentam a ergonomia como conhecimento fundamental a um modelista. Porém, Menezes e Spaine (2010) trazem que os cursos de moda do Brasil nem sempre oferecem esse conhecimento como preliminar para o ensino da modelagem. Com isso, observa-se que a palavra ergonomia, usabilidade e antropometria está presente no discurso de pessoas da área, apesar de que nem sempre são corretamente aplicados e muito produto do vestuário ainda carece de características ergonômicas. Isso é reflexo de um ensino incipiente da disciplina.

Uma questão também problemática em relação ao ensino da modelagem foi a trazida por R11 e R14. Em que os alunos que possuem a disciplina de modelagem na sua formação de designer de moda não direcionam muita atenção para tal. No entanto, ao ingressar no mercado de trabalho, sentem a necessidade de retomar os estudos na disciplina porque, mesmo que sua carreira se direcione para a área da criação, o conhecimento de modelagem não pode ser dissociado.

Os entrevistados da pesquisa ressaltaram suas experiências em confecções como importantes para o desenvolvimento profissional como modelista. Como a modelagem consiste em atividade prática é necessário que o exercício da função seja constante para o aperfeiçoamento profissional. Dessa forma, assim como apontado por R09, a tentativa e erro se faz presente quando uma metodologia não se aplica ao caso. Afinal, para atender à demanda de mercado por novidade, como sugere Santos (2015), torna-se primordial que o desafio pelo desenvolvimento de novos métodos seja adotado.

Com isso, o artigo contribui para traçar o panorama do ensino de modelagem nos cursos de moda em duas importantes regiões de Santa Catarina, a região da Grande Florianópolis, que abrange a capital do estado, e também o Vale do Itajaí. As informações abordadas são fundamentais para orientar professores e empresas, seja para aperfeiçoar a condição atual ou para se posicionar com base na diferenciação no cenário nacional.

A pesquisa se limitou a entrevistar professores que ministram a disciplina de modelagem e pesquisar a percepção com vista para a área que lecionam. Porém, a percepção de alunos e do mercado de trabalho podem contribuir para ampliar outras questões que não foram identificadas. Desse modo, dado o exposto e as dificuldades percebidas no decorrer da pesquisa, recomenda-se também para estudos futuros, um aprofundamento nos estudos que abrangem as metodologias no ensino de modelagem. Investigar a origem da falta de interesse dos alunos e buscar uma correlação com os métodos pode ser esclarecedor. Sugere-se, também, que pesquisas com o objetivo de identificar métodos de equipe de desenvolvimento de produto de moda possam ser objetos de estudo para compreender como ocorre a dinâmica da área de criação e modelagem sob o olhar da gestão de pessoas. Além disso, pesquisar a 
percepção de profissionais da área de moda, estilistas, modelistas, costureiras, empresários, entre outros, sobre a ergonomia seria de interesse para a área acadêmica a fim de poder orientar cursos de formação de moda.

\section{REFERÊNCIAS}

BEDUSCHI, Danielle Paganini. Diretrizes para o ensino de modelagem do vestuário. 2013. 205 p. Dissertação (Mestrado) - Escola de Artes, Ciências e Humanidades, USP, São Paulo, 2013. Disponível em: < http://www.teses.usp.br/teses/disponiveis/100/100133/tde-19022014-213611/pt-br.php>. Acesso em: 25 ago. 2016.

BEDUSCHI, Danielle Paganini; ITALIANO, Isabel Cristina. Descrição e análise da evolução dos métodos e obras de modelagem plana no Brasil: de 1960 aos dias atuais. Revista de Design, Inovação e Gestão Estratégica: Revista de Design, Inovação e Gestão Estratégica, São Paulo, v. 4, n. 2, p.1-20, 2 ago. 2013. Disponível em: < http:// www2.cetiqt.senai.br/ead/redige/index.php/redige/article/viewFile/203/250>. Acesso em: 25 ago. 2016.

BEZERRA, Germana Maria Fonenelle; MARTINS, Suzana Barreto. Equação da ergonomia no design de vestuário: espaço do corpo, modelagem e materiais. 2013. Disponível em: <http://coloquiomoda.com.br/anais/anais/2-Coloquio-de-Moda_2006/ artigos/107.pdf>. Acesso em: 25 ago. 2016.

FLETCHER, Kate; GROSE Lynda. Moda \& sustentabilidade: design para mudança. São Paulo: Senac, 2011. 192 p.

MENEZES, Marizilda dos Santos; SPAINE, Patricia Aparecida de Almeida. Modelagem Plana Industrial do Vestuário: diretrizes para a indústria do vestuário e o ensino-aprendizado. Projética, Londrina, v. 1, n. 1, p.82-100, dez. 2010. Disponível em: < http://www.uel.br/revistas/uel/index.php/projetica/article/view/7737/6858 >. Acesso em: 25 ago. 2016.

SANTOS, Virginia L. A.. Ministrando a disciplina de modelagem do vestuário. 2015. Disponível em: < http://www.coloquiomoda.com.br/anais/anais/11-Coloquio-de-Moda_2015/COMUNICACAO-ORAL/CO-EIXO2-ENSINO-E-EDUCACAO/CO-2-MINISTRANDO-A-DISCIPLINA-DE-MODELAGEM-DO.pdf>. Acesso em: 25 ago. 2016.

SILVEIRA, Icléia. Usabilidade do Vestuário: Fatores Técnicos/Funcionais. Moda Palavra E-periódico, Florianópolis, v. 1, n. 1, p.21-39, jul. 2008. Disponível em: < http:// www.revistas.udesc.br/index.php/modapalavra/article/view/7566/5070 >. Acesso em: 25 ago. 2016.

SOUZA, Patrícia de Mello. A modelagem tridimensional como implemento do processo de desenvolvimento do produto de moda. 2006. 116 p. Dissertação (Mestrado) - Curso de Faculdade de Arquitetura, Artes e Comunicação, Unesp, Bauru, 2006. Disponível em: < http://repositorio.unesp.br/bitstream/handle/11449/96266/ souza_pm_me_bauru.pdf?sequence=1\&isAllowed=y>. Acesso em: 25 ago. 2016. 